\title{
A wastewater retention canal as a sewage network and accumulation reservoir
}

\author{
Józef Dziopak ${ }^{1, *}$ \\ ${ }^{1}$ Rzeszow University of Technology, Department of Infrastructure and Water Management, \\ al. Powstańców Warszawy 6, 35-959 Rzeszów, Poland
}

\begin{abstract}
The paper presents an innovative retention canal for storm sewage as a competitive solution in relation to the ones currently used. The principle of operation of the retention canal, the conditions of its use in a sewage network and the basis for dimensioning were presented. To demonstrate its versatility and retention efficiency, comparative studies on the example of a drained catchment were carried out. A linear network layout composed of 12 storm canals with the retention reservoir located at the network outlet was assumed. Based on the developed algorithm, simulation tests were performed with the use of the SWMM 5.1 program. On the basis of hydrodynamic modelling it was determined: (1) the required geometry of storm canals, (2) the geometry of damming partitions and (3) the process of wastewater accumulation in the retention canal. Having the results of simulation research for rainfalls with a duration of 10 to 100 minutes, the critical rainfalls for network and retention canal dimensioning were determined. The comparison of hydrographs of sewage outflow from the examined catchment is interesting. From the value of $3.62 \mathrm{~m}^{3} / \mathrm{s}$ in the network it decreases three times to just $1.16 \mathrm{~m}^{3} / \mathrm{s}$ at the outlet of the retention canal. The retention canal with diameters identical to those established for the network, allow achieving the sewage retention capacity, which corresponds to a capacity of $1,844 \mathrm{~m}^{3}$ for a multi-chamber retention reservoir. Thus, the retention canal fully replaces the operation of a network of certain geometry and retention reservoir. The results of the research allowed the formulation of a number of important conclusions, including conclusions on cognitive significance. The critical rainfall appointed for the design of the retention canal always lasts longer than that, determined for the sewage network design. The retention canal is suitable for widespread use in the canals of new and already existing storm sewage systems and combined sewage systems. ${ }^{*}$
\end{abstract}

\section{Introduction}

The commonly used gravitational storm sewage system and combined sewage system are designed for strictly defined rainfall intensity in order to determine the geometry of sewers in a sewage network $[1,2,3]$. The very high quantitative variability of storm sewage flow during and after precipitation in any network cross-section determines the very low use of

\footnotetext{
*Corresponding author: jdziopak@prz.edu.pl
} 
its retention capacity. In the case of rainfalls of a short duration, the highest located canals are used to the greatest extent. On the other hand, in the case of long-lasting rainfalls, the large canals located lowermost are hydraulically most heavily loaded [4].

Simplifying, the sewage network can be compared to a one-chamber reservoir without outflow throttling, which generates the formation of the retention phenomenon due to its considerable length and the existence of many side canals [5]. This is illustrated by the changing shape of the hydrograph in subsequent sections of the lower located canals, which becomes more flattened along with the extent of a sewage network.

The retention capacity of the network is significant and includes the collectors and wells. The change of the hydrograph shape of sewage flow in the network can be reached mainly due to the retention reservoirs $[1,6,7]$. Being cubature objects, they are expensive and require large areas for their construction $[8,9]$. Bearing this in mind, the authors of this innovative solution [10] have developed a retention sewage canal. Its hydraulic system allows the full usage of sewage network retention capacity, ensuring almost complete filling with sewage.

The use of a retention capacity of sewage network gives practical and economically measurable effects, which may be determined using different methods [11, 12]. The most important benefits include the following:

- it allows a reduction of the impact of sewage discharge on the water receiver by distributing its intensity in a longer time interval;

- it enables the connection of additional sewage networks to the existing system without the necessity of using retention facilities;

- it significantly reduces and equalizes the sewage flow throughout the entire network, up to the sewage treatment plant;

- it limits the required retention capacity of cubature objects interacting with the network, and in favorable situations, it is even possible to omit them in the design concept.

\section{Retention sewage canal}

The retention sewage canal [10] is characterized by the division of the internal space of a typical sewage network length into separate chambers by means of partitions (Figure 1). These partitions are placed perpendicular to the direction of sewage flow in fixed sewage wells. The lower edge of each partition has a flow opening of a specific surface and shape, located at the bottom of the canal (Figure 2). The upper edge of the partition is finished with a typical frontal overflow.

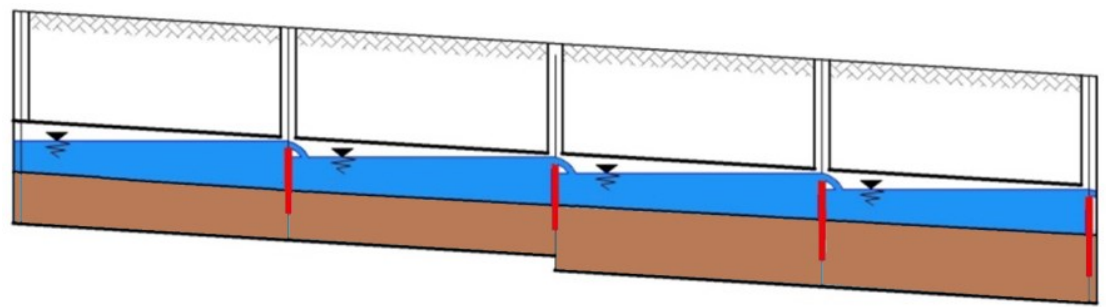

Fig. 1. Schematic of a retention canal with damming partitions with sewage retention space (average distribution of the effluent table in sewage network canals - brown colour; effluent distribution and retention capacity of the network after its transformation into a retention canal - blue colour).

Partitions dividing the internal space of the network into a system of retention chambers (tanks) are rigid plates fixed to the side walls of sewage chambers or as flexible plates fixed in the zone of their upper edges to the walls of sewage well chambers. The filling of the sewage retention chambers can be provided from the partition located uppermost or 
lowermost. The canal starting the retention from the uppermost chamber works more efficiently, and the flow openings increase their surface in subsequent chambers up to the lowest one. The sewerage network transformed into a retention canal corresponds to a certain number of single-chamber reservoirs operating in series. The sewage inflow to separate chambers of the canal is the sum of sewage flowing from the uppermost chamber and the sewage flowing from the part of the drainage basin.

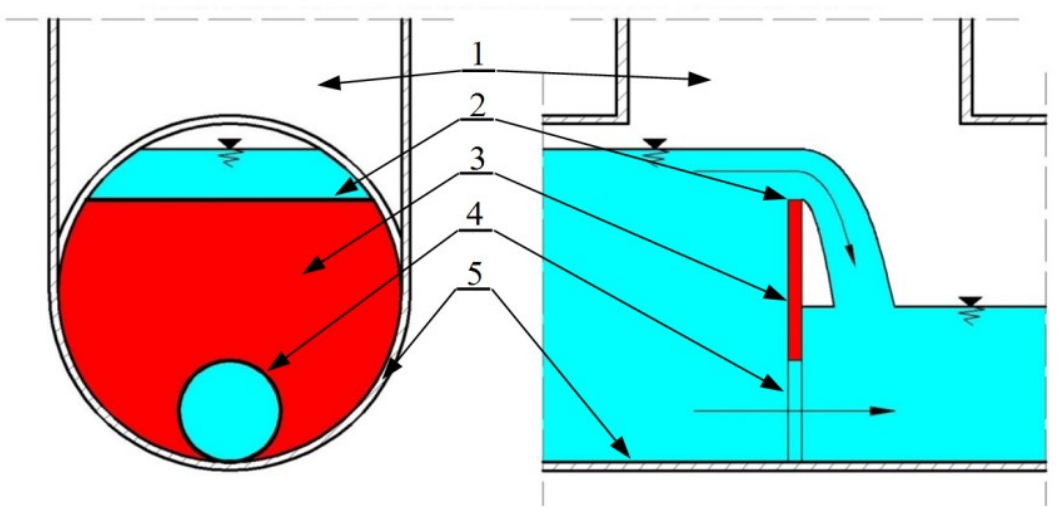

Fig. 2. Schematic of the execution and arrangement of damming partitions in a sewage well [1] (cross section, longitudinal section, 1 - damming partition, 2 - canal, 3 - flow opening, 4 - emergency overflow, 5 - well/sewage chamber).

The effective retention of stormwater sewage in canals already in service can be ensured after they are equipped with damming partitions. The geometry of new retention canals is set for three different design variants. The first assumes the stormwater disposal from the catchment at the lowest possible cost, including canal retention. The second is based on the designing of retention canals within a typical network, using the methods of determining stormwater calculative flows. This variant allows obtaining a definitely reduced sewage outflow from the catchment. The third variant requiring more complex calculation procedures, the canal cross-sections along the whole network length are selected with such dimensions, that at the outflow from the catchment (outlet of the last collector) will allow achieving the assumed value of reduced outflow $\beta \cdot Q d$.

\section{Basics of the dimensioning of retention canals}

The resultant reduction of effluent intensity flowing through the outlet of the last canal is a key parameter. It determines the hydraulic efficiency after the use of canal retention. The design of a sewage retention canal consists in the selection and location of a number of damming partitions, determining the size of flow openings and emergency openings after establishment of the canal geometry. M. Starzec is the author of an algorithm for retention canal dimensioning which was elaborated using the SWMM 5.1 program for hydrodynamic sewage network modelling [5].

The conducted simulation tests show that a greater efficiency of sewage retention canal can be obtained if: (1) damming partitions are located closer to each other, (2) canals have a smaller inclination and, obviously, (3) they have a larger dimension.

The most complicated stage in the design of a retention sewage canal is the correct selection of the variable geometry of the flow openings in the separate partitions. It is different each time and depends on the level of overflows location and assumed maximum filling of the canal, for example up to $90 \%$ of its diameter. 
The optimal solution is to select the surface of individual flow openings in such a way, so that each time the strictly determined critical rain obtains the largest volume of sewage accumulated in the retention canals. The measurable effect will be the minimum value of sewage flow intensity at the outlet of the canal equipped with the last flow opening.

The research was carried out assuming a linear arrangement of 12 canals on the drainage catchment, in which a proportional increase of the drained urbanized surface takes place along the system of canals. A multi-chamber retention reservoir is located at the outlet of the last channel, (Figure 3).

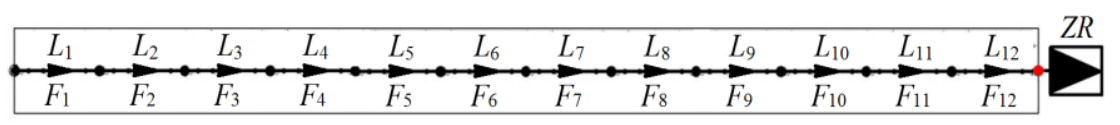

Fig. 3. Schematic of a linear layout of a storm sewage network $(F 1=F 2=\ldots F 12=3$ ha; $L 1=L 2=$ $\ldots=L 12=360 \mathrm{~m} ; i_{k}=$ const $=3.33 \%, Q d / Q c \approx 0,9 ; Z R$ - multi-chamber storage reservoir).

The adopted sewage system schematic enables an objective comparison of the processes of flow formation and stormwater accumulation in various design configurations in order to investigate the influence of the arrangement of retention canals on their retention efficiency. The first one concerns the transport of stormwater sewage in a traditional gravitational stormwater network. The second refers to a stormwater sewage system transformed into a system of retention canals equipped with throttling partitions for the sewage flow. In this variant, the flow may take place only in the bottom zone or both in the bottom zone and through the emergency overflow in the roof section of the canals.

As part of the assumptions made, simulation studies were carried out using the formulated algorithm of hydraulic processes description [5], based on hydrodynamic modelling. It takes into account the stages of conversion of rainfall into catchment surface runoff up to the flow in closed gravitational canals discharging the storm sewage and its retention. Taking into account the determined calculative stormwater flow intensity in the final cross-sections of separate canal sections, the required geometry of canals was determined, meeting the required hydraulic demands, which ensure their proper functioning.

\section{Results and analysis of simulation research}

The implementation of an innovative solution in the form of a retention canal system gives unlimited possibilities for solving complex design tasks, especially in catchments covering the central districts of cities. The installation of damming partitions in the inspection and control wells with well-defined geometry will significantly increase the hydraulic network capacity at all stages of sewage transport. In particular, this applies to stormwater discharged to the water receivers and to combined sewage transporting to the equalizing reservoir and wastewater treatment plant.

The analysed design concept assumes the necessity of stormwater outflow reduction from the drained catchment to the lower situated network (below the reservoir $Z R$ ). For this purpose, two concepts have been established that ensure the assumed outflow reduction.

The first task is to use a multi-chamber retention reservoir at the end of the storm reservoir (Figure 1). The volume of the reservoir is to ensure the permissible stormwater outflow, providing a certain value of the flow reduction coefficient. In the second solution, a designed sewage network was adapted to the system of retention canals, taking into account the fixed spacing of damming partitions. Such scientific goals require the solving of many different partial tasks and the fulfillment of project recommendations. 
The formulated program [5] allows optimizing the cross-sections of bottom openings, corresponding to the admissible canal filling height, adopted as $90 \%$ of the canal diameter. The advantage of simulation tests is also the determination of the of storm sewage volume, which will be accumulated temporarily in the retention canals.

With the results of simulation tests using the SWMM 5.1 program for hydrodynamic modelling, the storm sewage volume was determined for different rainfall durations. In consideration of the rainfalls lasting from 10 to 100 minutes, the following stormwater volumes were investigated: (1) flowing from the drainage catchment to the sewage system of the assumed schematic, (2) at the outlet of the last canal located at the end of the drainage catchment and (3) at the outlet of the retention canal equipped with partitions with fixed flow openings (Figure 4). The comparison of the values of the determined flows proves, that after transformation of a traditional network with a fixed geometry of 3.62 $\mathrm{m}^{3} / \mathrm{s}$ into a retention canal it is possible to reduce the calculative flow to just $1.12 \mathrm{~m}^{3} / \mathrm{s}$, thus more than three times. The calculative flow $Q d=3.62 \mathrm{~m}^{3} / \mathrm{s}$ in the outflow collector was set at critical rainfall duration $t m=15$ minutes, while the reduced flow in the retention canal $Q z=1.16 \mathrm{~m}^{3} / \mathrm{s}$ was determined during a critical rainfall duration $T K R=44$ minutes (Figure 4).

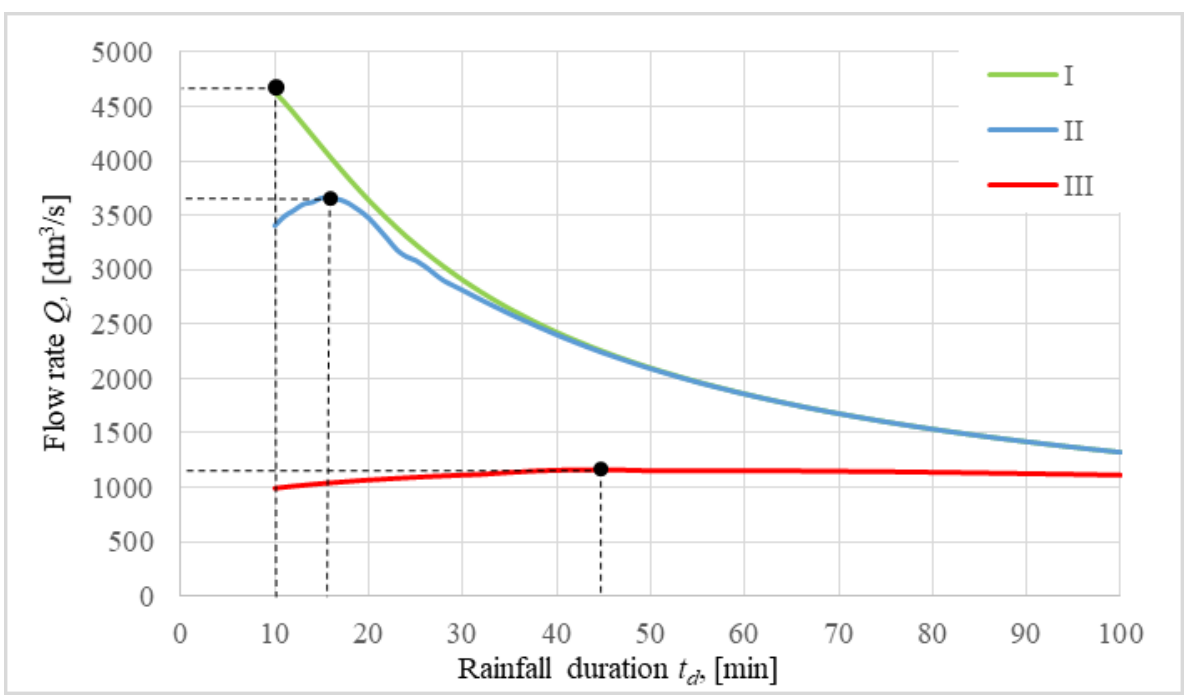

Fig. 4. Stormwater outflow hydrographs for the examined drainage catchment (I - last canal outlet, II - the retention canal outlet, III - from the drainage catchment).

Considering the variant, it was assumed that stormwater from the newly designed catchment can be discharged into the already existing sewage system just after the outlet of the final collector with an intensity of not more than $1.16 \mathrm{~m}^{3} / \mathrm{s}$. For this purpose, a cubature object was used in the form of a multi-chamber retention reservoir, which will provide the temporary retention of stormwater sewage, and on the outflow - the flow intensity of $Q z=$ $Q d \cdot \beta=3.62 \cdot 0.32=1.16 \mathrm{~m}^{3} / \mathrm{s}$. The appropriate required reservoir volume (Figure 5) was determined as required for different rainfall duration in the range of 10 to 100 minutes. With such assumptions, its necessary usable capacity $V W=1,844 \mathrm{~m}^{3}$ was determined under the critical rainfall duration of $T M W$ time $=37$ minutes $[8,11]$ by hydrodynamic simulations. Based on the formulated model and the simulations carried out, three hydrographs of stormwater sewage flow were established: from the catchment to the network (Series 1), in the final collector of the designed network (Series 2) and at the end of the retention canal (Series 3). They were determined on the basis of performed 
simulations when analysing rainfall of a short duration of 10 minutes (Fig. 6). There are very large differences in flows throughout the analysed period (Series 1, 2 and 3). On the other hand, the use of a retention canal ensures a huge reduction of flow (Series 2) as a result of using the whole capacity of the retention canal.

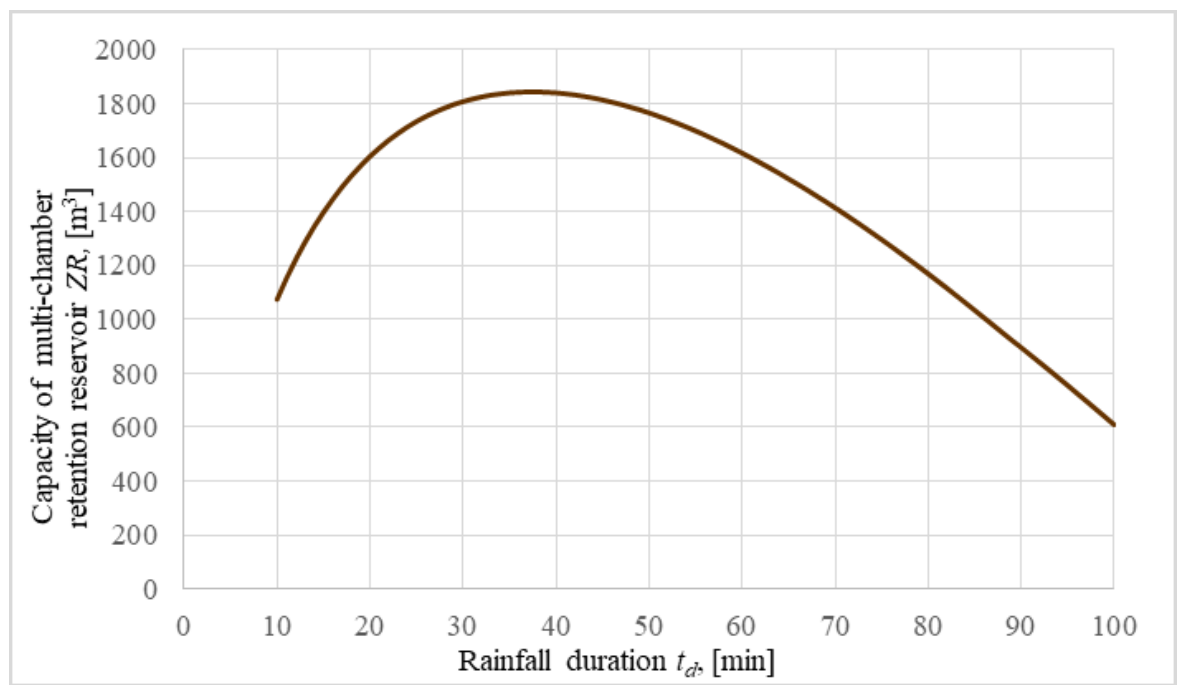

Fig. 5. The envelope of the determined usable capacity of multi-chamber retention reservoir $Z R$ located below the drained catchment.

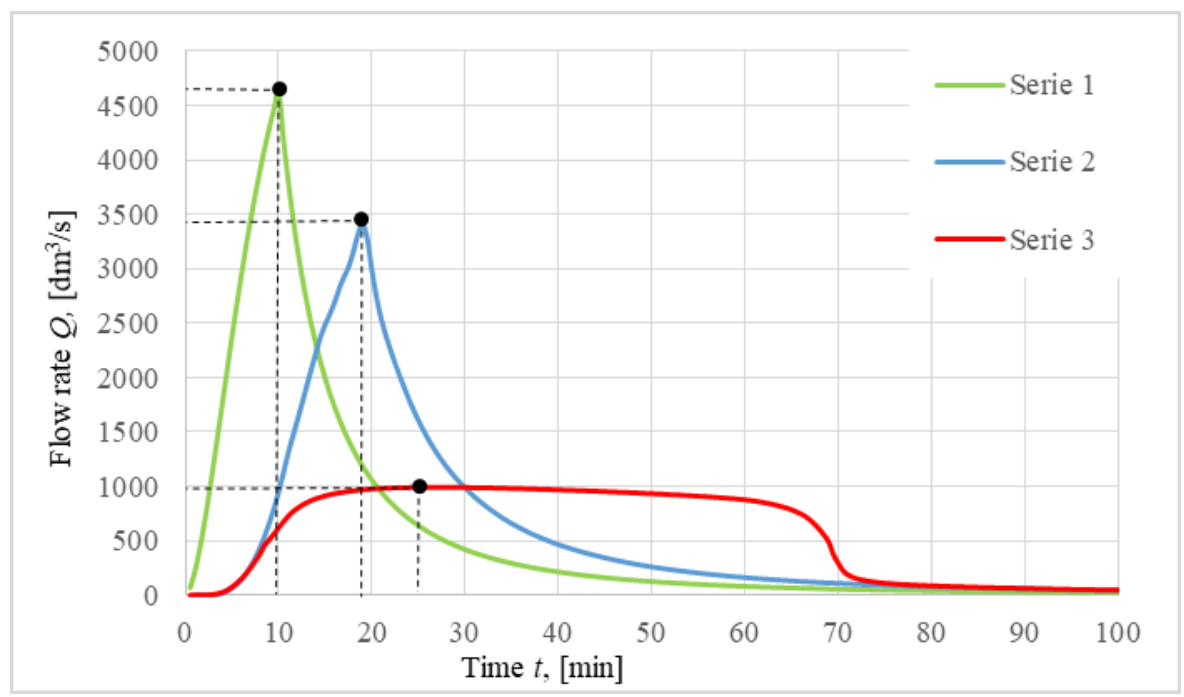

Fig. 6. Hydrographs of stormwater sewage outflow from the drained catchment during rainfall of a 10 minutes duration (Series 1 - from the catchment to the network, Series 2 - at the outlet of the retention canal, Series 3 - in the outflow collector).

Another example of the possibilities provided by the algorithm formulated using the SWMM 5.1 program [5] are the simulations of flow fluctuations during rainfall of calculative duration for the retention canal dimensioning (Figure 7).

The value of $T K R=44$ minutes and differs from the one defined as critical for storage reservoir dimensioning with the duration $T M W=37$ minutes. Its value is greater than the critical one determined for the storage reservoir. In the analysed sewage network equipped 
with damming partitions, significantly lower sewage flow rates are observed over the entire time interval, also in the final section of the outflow collector from the new drainage basin.

The analysis also covered precipitation of a longer duration $T d=100$ minutes. It turns out that in this case the outflows from the catchment and the flow in the final canal are relatively small and are close to the flow intensity that will occur at the outlet of the retention canal.

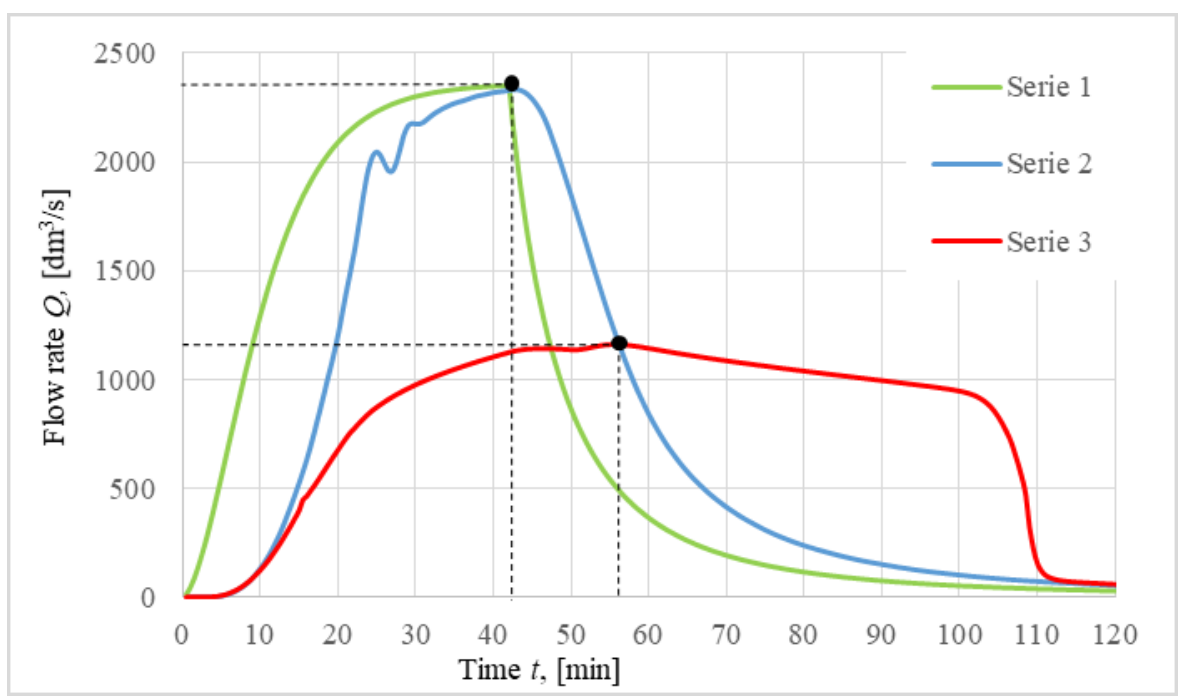

Fig. 7. Hydrographs of storm sewage outflow from the drainage basin during rainfall of 44 minutes duration (Series 1 - from the catchment to the network, Series 2 - at the outlet of the retention canal, Series 3 - in the drainage collector).

This example, as well as other simulated calculation cases, confirms the stability of the flow, which is formed as a hydrograph shape along the length of the retention canal, regardless of the rainfall duration. However, the calculative times of the duration for retention canals dimensioning are always longer than the times that are set for the design of storage reservoirs.

\section{Summary and final conclusions}

The transformation of gravitational sewage systems into systems of retention canals will allow, in practice, a significant flattening of outflow hydrograph of storm and combined sewage flowing away from subsequent fragments of the network. In addition to an increase in the existing network hydraulic capacity, retention canals contribute to the hydraulic relief of sewage network facilities, including: storm overflows, storage reservoirs, siphon passages, pumping stations and others.

Indirectly, the retention canals fulfill a special role in improving the water receiver's quality which is affected by the discharges of combined sewage from storm overflows. As a result of canal retention, the outflow of sewage is delayed, which results in the flattening of the hydrographflow shape, and this phenomenon provides a significant reduction of outflow rate and annual number of discharges from overflows. The simulation tests carried out with the use of the formulated algorithm allowed performing a number of partial tasks. Their effect is the confirmation of the research thesis of cognitive significance. The wide range of analysed cases allows for the formulation of several conclusions of general and practical significance. 
1. The retention sewage canal allows using the free space in sewage network canals and provides the possibility of the retention of significant sewage volumes.

2. The implementation of a retention sewage canal leads to a significant reduction of the investment costs of a traditional sewage system, especially those requiring the use of retention facilities.

3. The retention sewage canal does not require an external energy supply, and its operation is maintenance-free and does not generate operation costs.

4. To transform the canal into sewage retention chambers, a commonly available series of pipes are used. Based on previous experience on the implemented objects, it is recommended using pipes produced with PEHD technology. This material allows the welding of partitions with a canal structure, that additionally and significantly strengthens their construction and improves their strength parameters.

\section{Literature}

1. J. Dziopak, Multi-chamber storage reservoirs in the sewerage system (TUC, Czestochowa, 1997)

2. K. Pochwat, D. Słyś, S. Kordana, J. Hydrol. 549, 501-511 (2017)

3. T. G. Schmitt, M. Thomas, N. Ettrich, J. Hydrol. 299, 300-311 (2014)

4. D. Słyś, Zrównoważone systemy odwodnienia miast (DWE, Wrocław, 2013)

5. M. Starzec, J. Dziopak, D. Słyś, Underground Infrastructure of Urban Areas 4, 193-200 (2018)

6. M. Starzec, J. Dziopak, Underground Infrastructure of Urban Areas 4, 181-192 (2018)

7. K. Pochwat, E3S Web Conf. 17, 00075 (2017)

8. D. Słyś, J. Dziopak, Pol. J. Environ. Stud. 20, 743-753 (2011)

9. D. Słyś, J. Dziopak, A. Raganowicz, Underground Infrastructure of Urban Areas 3, 253-260 (2015)

10. D. Słyś, J. Dziopak, Retencyjny kanał ściekowy, Patent no. 217405. Urząd Patentowy RP, Warszawa (2013)

11. Kordana, D. Słyś, J. Dziopak, J. Clean. Prod. 82, 58-69 (2014)

12. A. Stec, D. Słyś, Ecol. Chem. Eng. S 20, 381-396 (2013) 